\title{
Arabic Linguist Perspective on Ibn Jinni's Ideas About Derivation: Comparative Study of Al-Suyūțī and Emīl Badī' Thought
}

\section{Alsuna: Journal of Arabic and English Language}

\section{Nahdliyyatul Azimah \\ Universitas Islam Negeri Sunan \\ Ampel \\ @ nahdliyyah.nafi@gmail.com}

\section{Keywords: \\ Al-Ishtiqāq/Derivation \\ Ibn Jinnī \\ Emīl Badī' Ya'qūb \\ Al-Suyūțī}

Article Information:

Submitted: April 12, 2020

Accepted: April 20, 2020

Approved: May 21, 2020

\section{Abstract}

Purpose - This research aims to illustrate the views of Al-Suyūți and Emīl Badī' Ya'qūb about the thought of derivation according to Ibn Jinnī, as well as the location of the similarities and differences between their thoughts.

Design/methodology/approach - This research study relies solely on literary studies or documentation of manuscripts, especially the works of Ibn Jinny, Al Suyuti, and Emīl Badi' Ya'qūb.

Findings - The result of this study that three linguists (Ibn Jinnī, AlSuyūțī, and Emīl Badī' Ya'qūb) agreed to challenge the definition of derivation. Al-Suyūți agreed to the thought of Ibn Jinny in the division of derivation. As for Emill, different opinions with the thought of Ibn Jinny in three things, namely: Ibdal, Naht (acronym), and the division of derivation. On the other side of Al-Suyūți denied the idea of Ibn Jinny in two respects, namely: derivation and naming of al-Ishtiqāq alAkbar.

Originality/value - Learners of Arabic language and religious studies students must study derivation science and are not confined to grammar and exclusivity. Because derivation science is an art that distinguishes the Arabic language from all other languages.

Paper type - Conceptual Paper

اللغة عبارة عن أصوات يعبر بها كل قوم عن أغراضهم، وقد تعددت أنواع الأصيوات وطرق التعبير

بتعدد الأمم واختلاف أصواتها (Ya'qūb 1982). وللغة العربية منزلة خاصة بين سائر لغات العالم. كما أن أهمية هذه اللغة تزداد يوما بعد يوم في عصرنا الحاضر (Al-Khūli 1998).

اللغة العربية هي إحدى اللغات السامية وأرقاها مبنى ومعنى و اشتقاقا وتركيبا، وهي من أرقى لغات

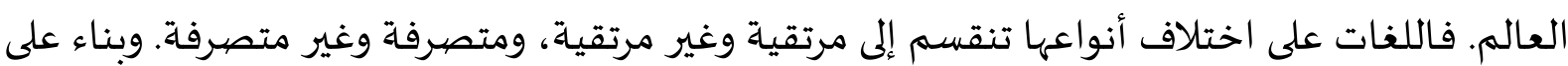
هذا تجدّد اللغات و إنّ هذا تقسم إلى ثلاث طوائف كبرى، منها: ( ) الآرية (r) الطورانية (ب) والسامية ، وفيها اللغة العربية والسريانية والعبرانية والفينيقية والقرطجنية والأشورية والبابلية وغيرها.وأرقى اللغات السامية هي اللغة العربية (1990 آنآرurj). 
رأى قدور بأن اللغاتِ السـاميةً من المجموعات اللغوية الأخرى بخصائص تجعل منها كتلة واحدة،

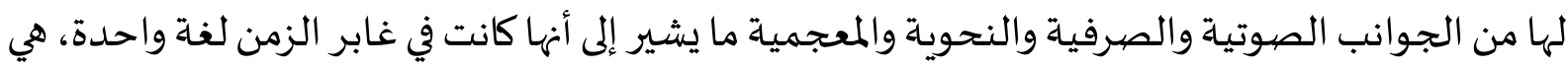
اللغة السامية الأولى أو العربية. وقال إميل 》وليس الاشتقاق من خصيائص العربية فحسب، بل إنها من أهمها

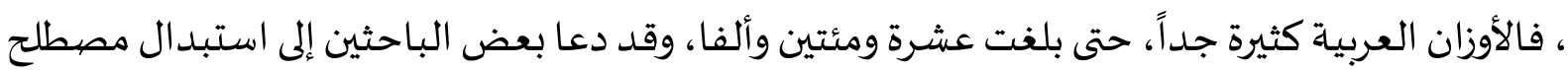
"الاشتقاق" بمصطلح "الصرف"، وإلى تقديم دراسة الاشتقاق على دراسـة النحو " . وهذه النظرية اختارها Page | بعض الباحثين، منها عبدالله أمين: أما الاشتقاق فهو شيء آخر غَيْرُ عِلْيَيْ النحو والصيرف. إنها علم يزيد اللغة

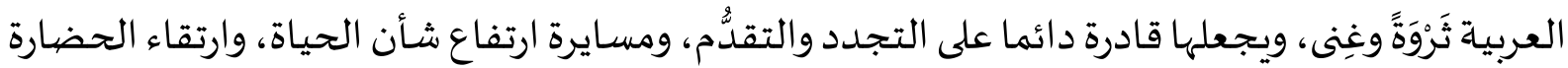
(Amīn 1956). وقد ذهب جمهور اللغويين في العصر الحديث إلى ضرورة الاشتقاق لنموّ اللغة وتطوّرها.

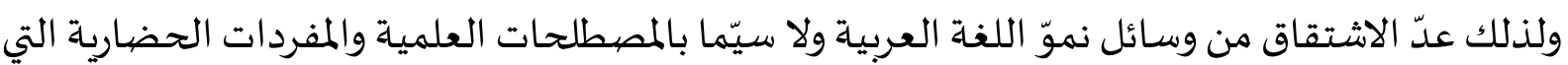
ينبغي أن تسدّ النقص في الثروة اللفظية أمام تسـارع الزمان الذي يأتي بكل جديد.

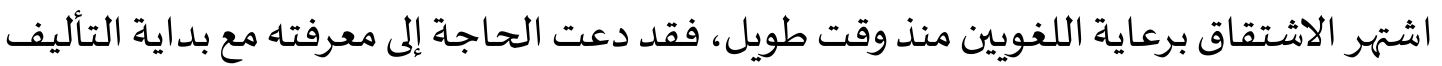

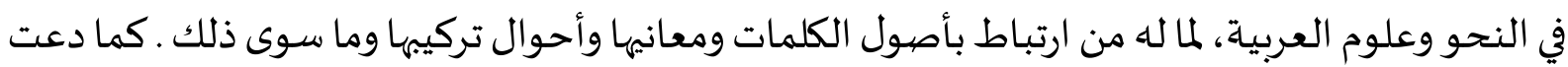
الحاجة إليه لمعرفة معاني الأسماء التي نقلها الناس عن العرب وجهلوا أصولها، وفي كتاب "المزهر" من هذا النحو أخبار تشير إلى عدم معرفة الكثير من اللغويين باشتقاق بعض الأسماء ، ومن أطرف ما ذكر سؤال أحد هم أبا عبيدة عن اشتقاق كلمة "منى" ، فقد قال : للسائل : لم أكن مع آدم حين علّماه الله الأسماء ، فأسـأله عن اشتقاق الأسماء (Al-Suyūṭi 2014) ويبدو أن جهل في أصول الكثير من الأسماء الاشتقاقية جعل

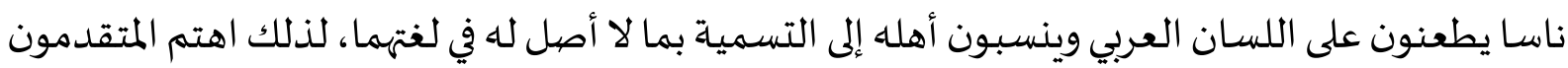
بتتبع اشتقاق الأسماء لكشف معانها على وجه التحقيق، وقد اتخذ هذا البحث وجهة واضحة حين ألّف عدد من اللغويين منذ القرن الثاني الهجري كتبا خاصية باشتقاق الأسماء (Qudūr 1993).

\section{طريقة البحث}

هذا البحث يسلك بالمنهج المقارن والدراسة المكتبية. بالمعنى، بحثت الباحثة عن البيانات التي

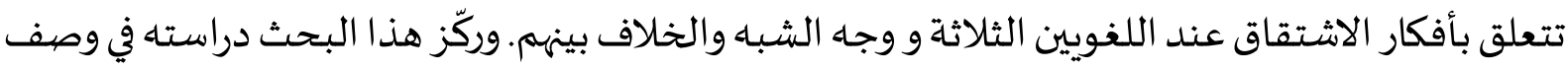

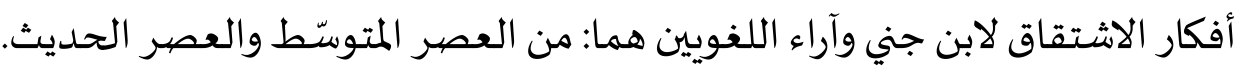

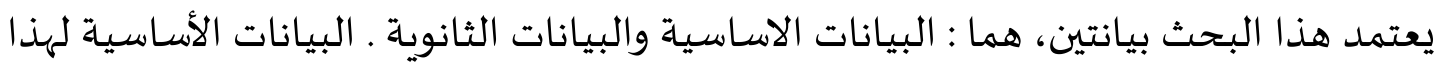
البحث هي كتب التي بحثت عن أفكار ابن جني في الاشتقاق. وأما البيانات الثانوية فهي البيانات التي تدعم البيانات الأسـاسية مثلا: كتاب المزهر لجالال الدين السيوطي، وكتاب فقه اللغة العربية وخصائصها لإميل بديع، و كتاب الخصائص لابن جني وما إلى ذلك. قارنت الباحثة نتائج الدراسـة عن أفكار الاشتقاق عند ابن جني و السيوطي وإميل بديع مع البيانات الأخرى المرتبطة بهذا البحث، مثلا: البحوث السـابقة و الوثائق و الكتب والمقالات العلمية والاسشار إلى المشرف والمعلمة التي لها كفاءة في علم الاشتقاق. 


\section{أحدث البحث وتميزه}

ومن البحوث السابقة التي رأت الباحثة أن لها علاقة بهذا البحث ما يلي :(1) بحث قامت باه للؤلؤ المكنونة (Maknunah 2008) تحت الموضوع » العلاقة بين المعاني وأحرفها للاشتقاق الأكبر أو القلب اللغوي

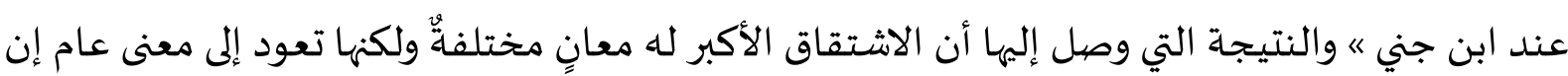
تباعد شيء من ذلك رد. (Y) عناية الرشيدة (9 . . Page | تحت الموضوع " دراسة مقارنة عن الاشتقاق عند ابن جني وعبد الرحمن جلال الدين السيوطي في المزهر " والنتيجة التي وصل إليها: قسّم ابن جني والسيوطي الاشتقاق إلى قسمين هما الاشتقاق الصغير والاشتقاق الكبير. وأما أصل الاشتقاق عند ابن جني يحتوي على خمسـة أمور و أما أصل الاشتقاق عند السيوطي يحتوي على ثلاثة أمور وطريقة الاشتقاق عند السيوطي لهمي تحتوي على خمسة عشر طرقا. وأوجاء الشباء بين الاشتقاق عند ابن جني والسيوطي وهي في سبعة أمور وأما أوجه الخلاف بين الاشتقاق عند ابن جني والسيوطي وهي في خمساة أمور(Rosyidah 2009). وعندما تلاحظ الباحثة المباحث لهذه المجلة، كانت البحوث عن علم اللغة لا تزيد على اثنين وهما بحث عن علم الأصيوات بين نظريات اللغويين القدماء والحديثة وبحث عن مميزات الإعجاز اللغوي عند ابن جني في القرأن الكريم

.(Fauzia 2019)(Zainuddin and Asy'ari 2019) الفرق الأسـاسي بين هذا البحث والبحوث السابقة أن الباحثة تقوم بملاحظة تطوير الاشتقاق من العصر المتوسط إلى العصر الحديث بدراسة مقارنة بيننظريات ابن جني و بعض اللغويين في الاشتقاق ، و

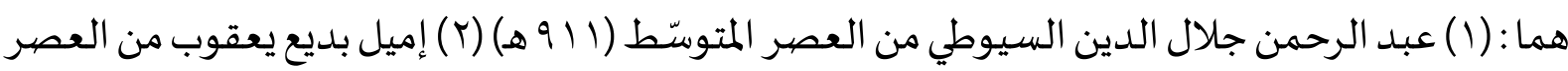
الحديث ( ـ 9 (1). لاتحدد الباحثة العصيور القديمة في هذا البحث لأن ابن جنى قد وكّل تلك العصيور. تجري عملية تعليم في الجامعات التي فيها قسم مخصص للغة العربية او تعليم اللغة العبية في اندونيسيا بشكل جيدٍ عموما، في ناحية خطة التدريس ،و منهج التعليم ، ومادة التعليم ، وكتب المقرّرات وما إلى ذلك. ولكنّ توجد نقطة الضعف في تعليم مادّة علم اللغة و هو عدم الإهتمام عن موضيوع الإشتقاق

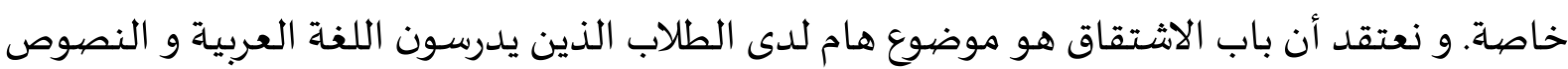
الدينية.

في هذا البحث أرادت الباحثة دراسة آراء اللغويين على الاشتقاق عند ابن جني نظراً إلى أهمية الاشتقاق في اللغة العربية. ابن جني رأى أن الاشتقاق نوعان: صغير وكبير. وهنا وضعت الباحثة تحديد دراستها في "آراء اللغويين عن الاشتقاق عند ابن جني" ، و اختارت اثنين منهم و هما : (1) السيوطي (11 (1)هـ)

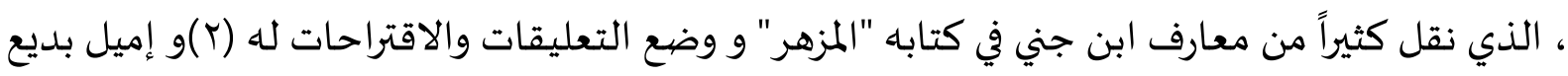

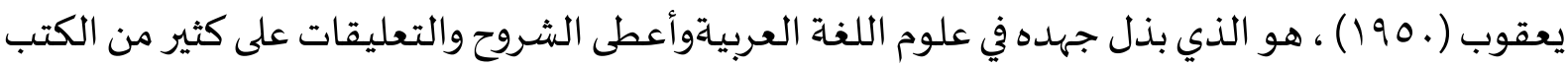
في اللغة العربية. وهما خبيران معروفان في هذا المجال، وآراءهما وثيقة في علوم اللغات وخاصة في دراسة الاشتقاق.

كان ابن جنيّ من أحد كبار الأدباء واللغويين ، مولده في الموصل و وفاتهببغداد. أخذ اللغة والآدب

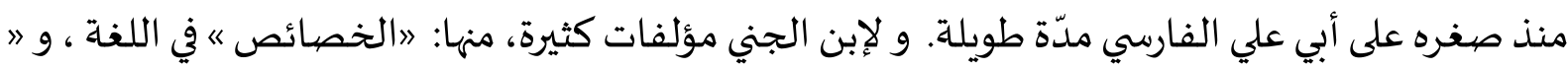


اللمح " في النحو و " سر صناعة الإعراب " و " شرح ديوان المتنبّي 《 في شرح 》 التصريف 《 للمازني وما إلى

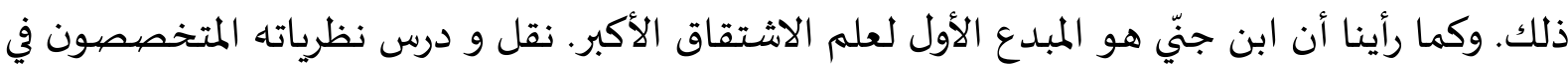

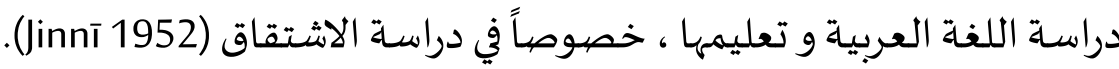

Page | 39

\section{المناقشة}

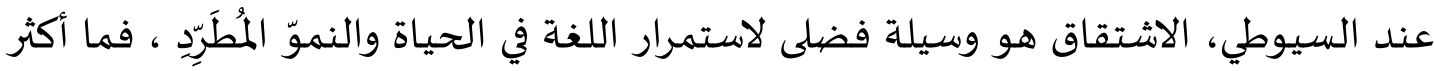

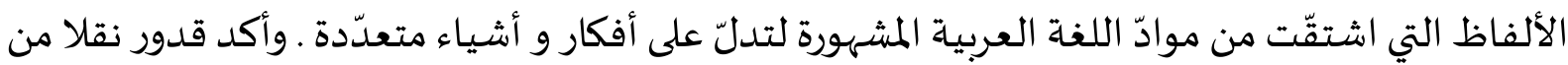

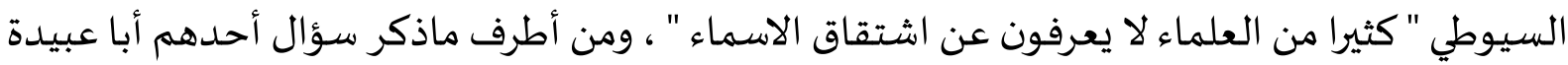

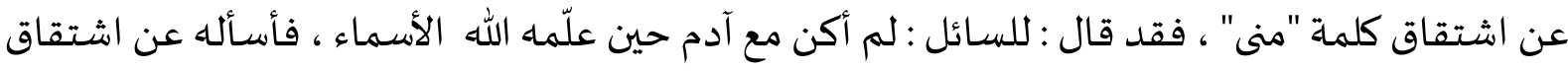

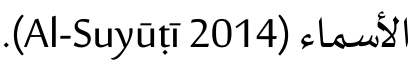

عند السيوطي الاشتقاق ينقسم إلى قسمين :( ) الاشتقاق الأصغر هو أخذ صيغةٍٍ من أخرى مع

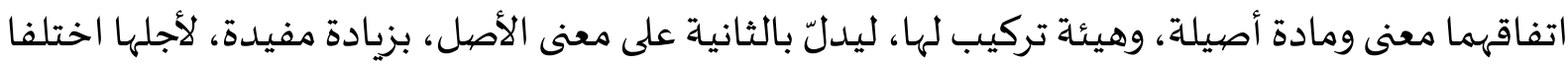

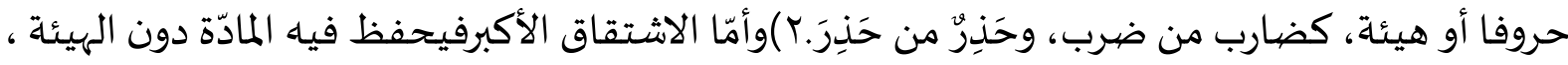
فيجعل (ق و ل) و (ل ق و) و (و ل ق ) و (و ق ل) وتقاليبها الستة ، بمعنى الحفّة والسرعارة .

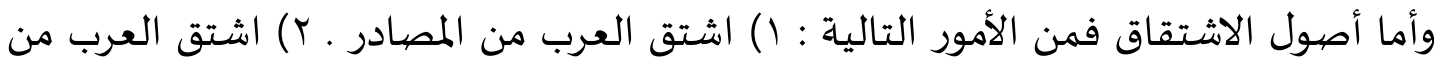
الجواهر أو الأسماء الأعيان ولكن قليل جدا. r) اشتق العرب من أسماء الأصهوات المسموعات.

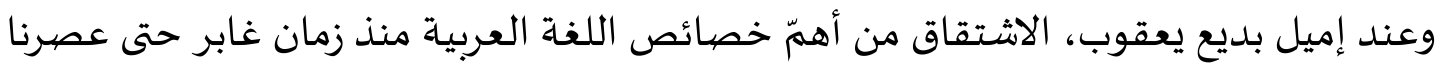
الحاضر. عرّف إميل الاشتقاق لغة واصطلاحا ـ في اللغة ، الاشتقاق هو أخذ شق الشيئ وهو نصفيه ،

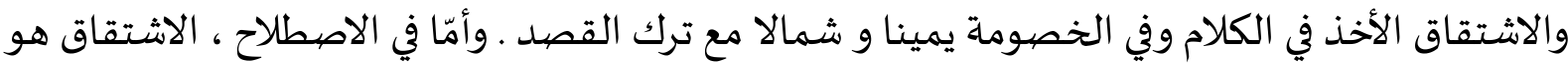

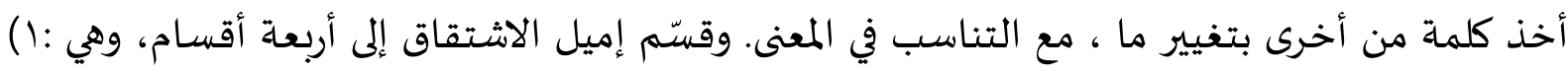

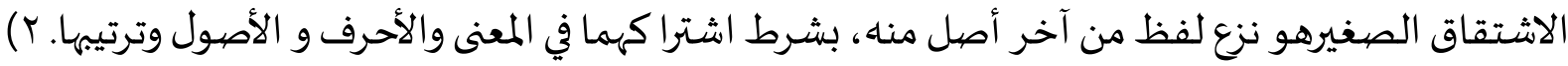

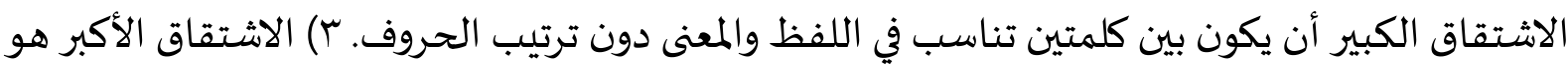

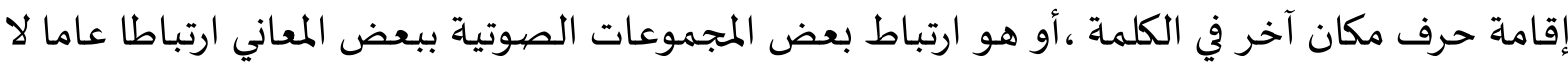

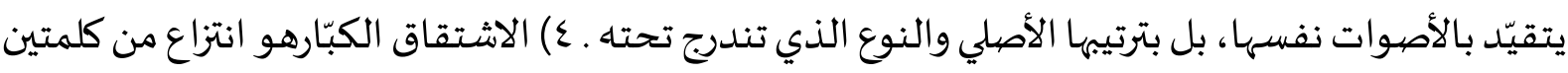

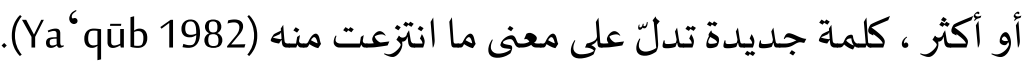

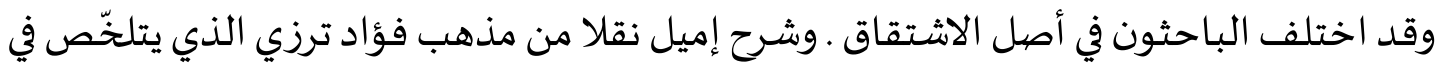

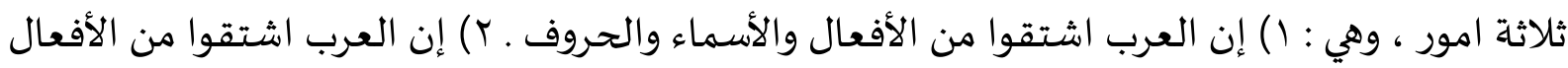

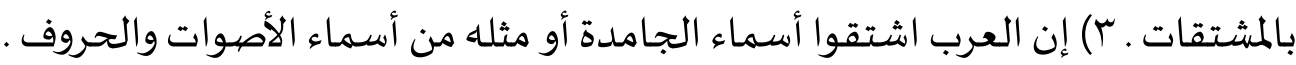

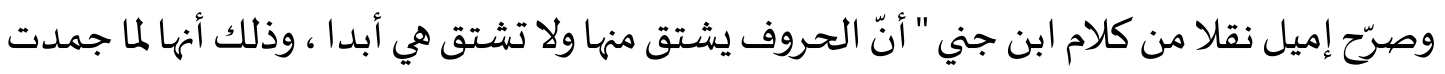

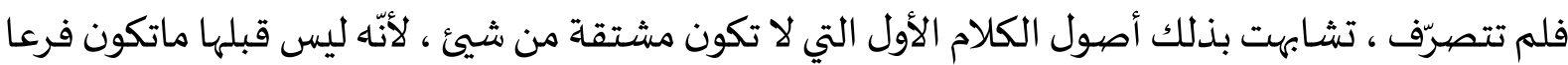

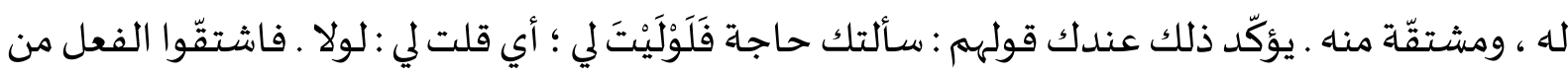


الحرف المركّب من لو ولا (Ya'qūb 1982). أي يستطيع الحروف مشتق ولكن مؤقت فحسب ، لأن ليس فرعا قبلها. أن العرب اشتقوا من الأفحال بالمشتقات .والمشتقات تحتوى على اسم المصدر، واسم المرة ، واسم ، واسم

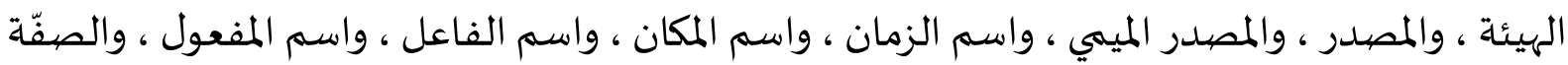

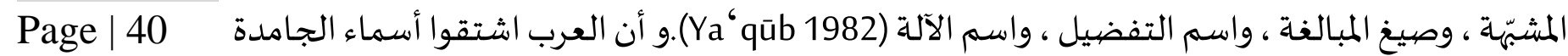

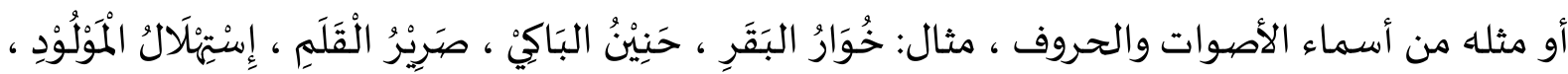
مُوَاءُ الهِِِّ.

يوجد وجاه الشبه و الخلاف بين آراء ابن جني و السيوطي في النواحي التالية:

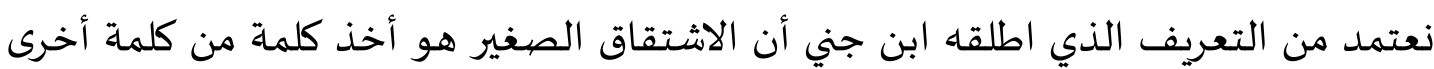

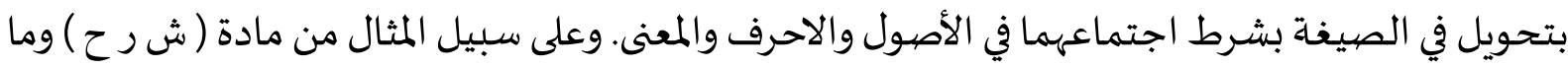

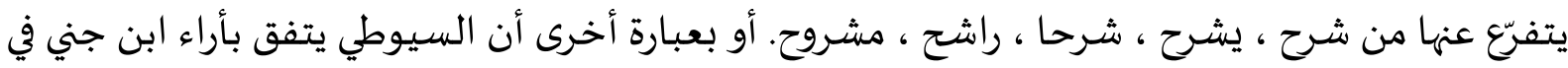

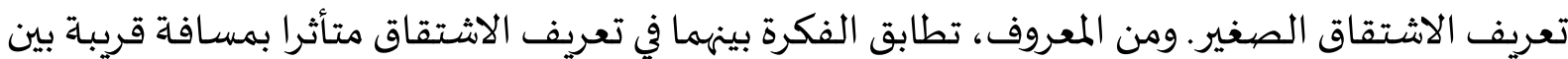

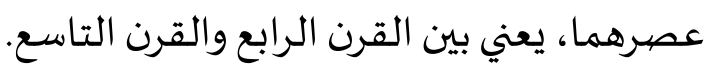

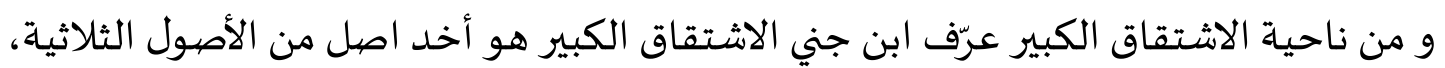

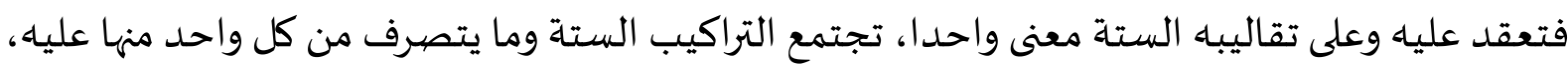

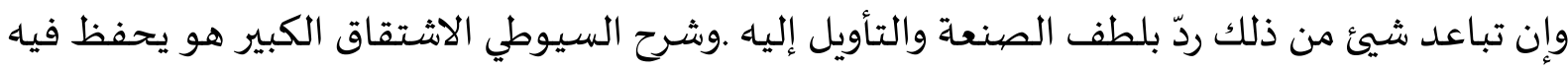
المادّة دون الهيئة ، فيجعل (ق و ل) و (ل ق و) و (و ل ق ) و (و ق ل) وتقاليهها الستة ، بمعنى الحفّة والسرعة.

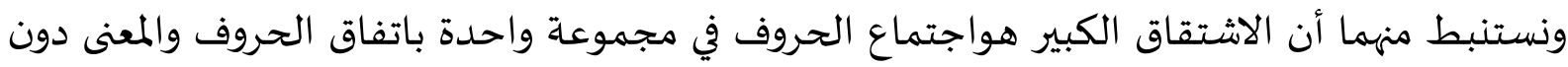

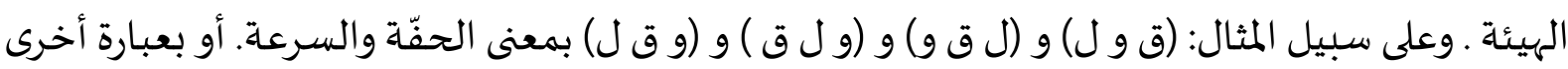

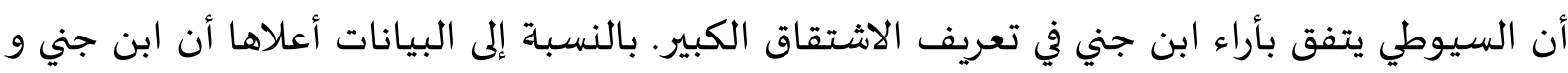

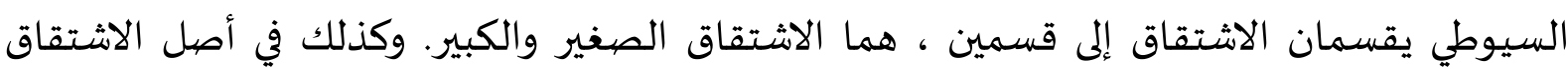

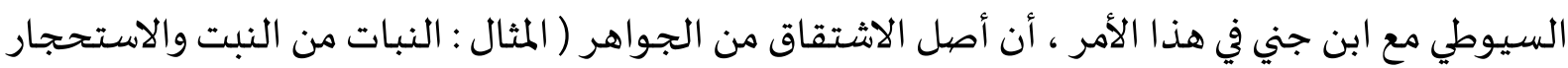

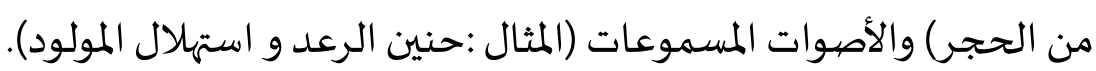

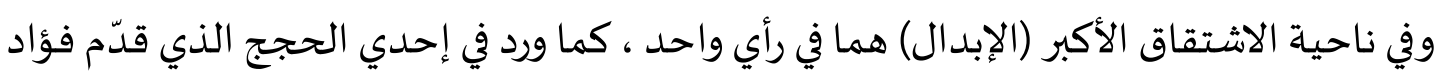

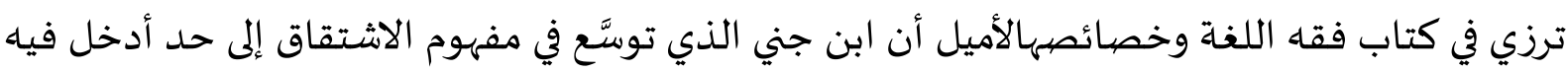

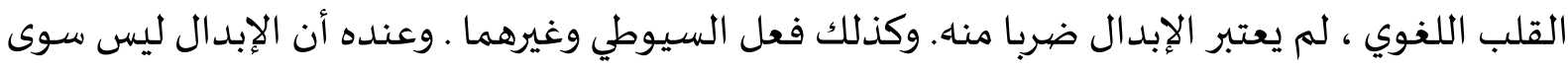

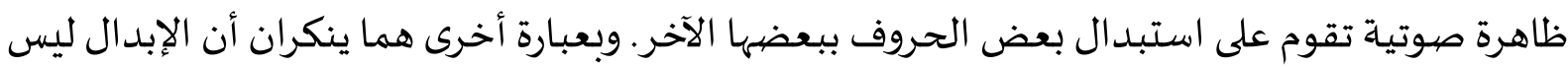

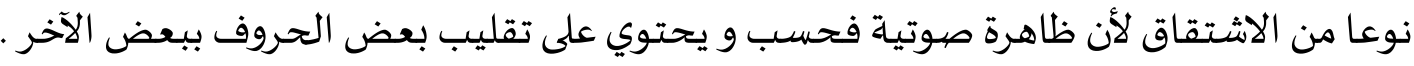

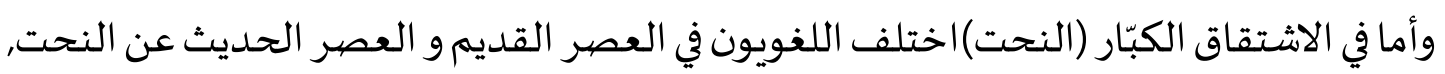

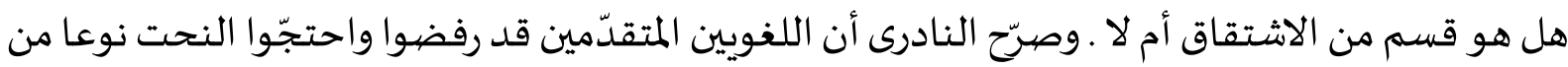

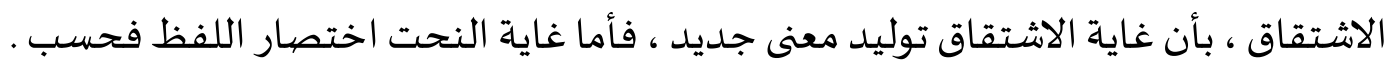




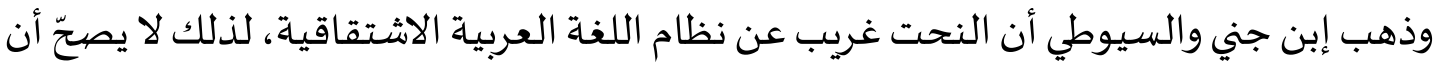

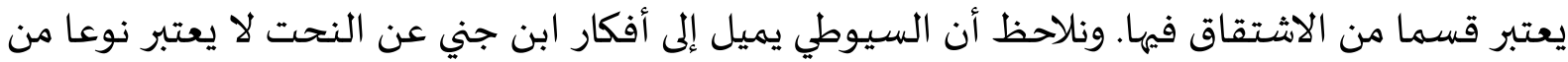

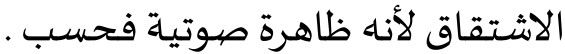

بعد أن عرفنا وجه الإتفاق بين ابن الجني و السيوطي سنعرض هنا نقاط الخلاف بينهما.حقيقة،

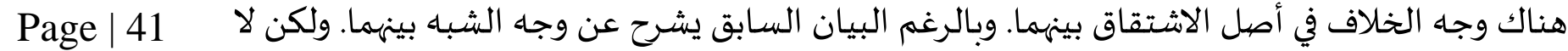

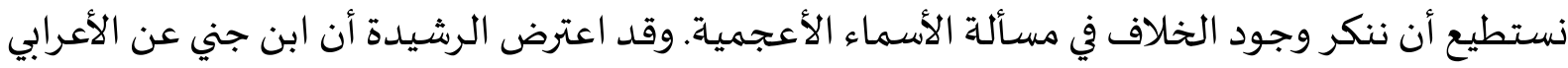

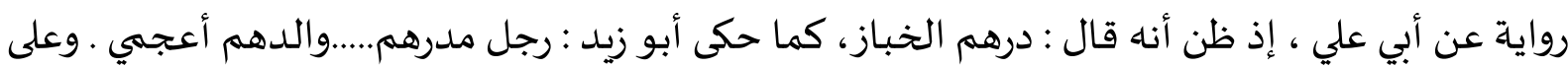

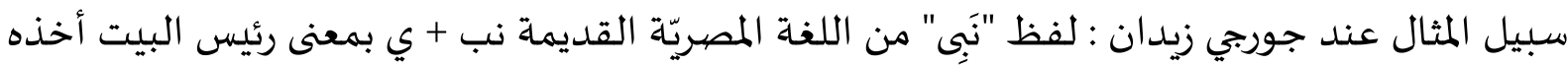

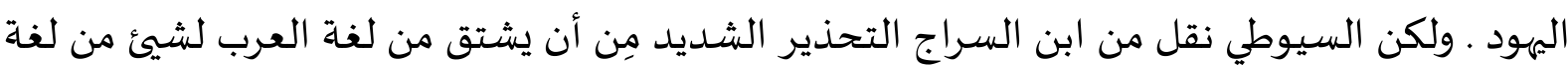

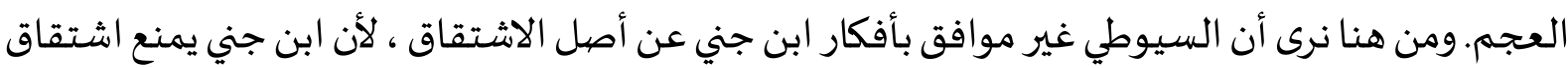

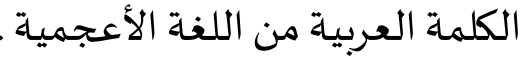

ونقد السيوطي تسمية الاشتقاق الأكبر عند ابن جني كما شرح الراجي (Ar-Rājihị̂ 1988) نقلا

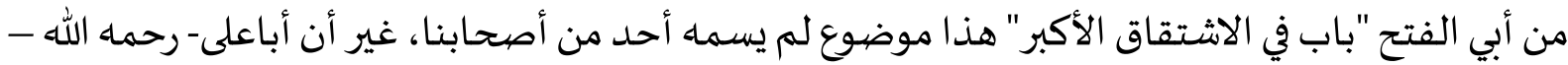

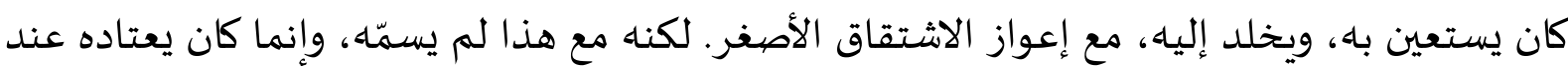
الضرورة، ويستروح إليه. وإنما هذا التقليب لنا نحن وسنراه فتعلم أنه لقب مستحسن. ويذكر السيوطي أنّ هذا النوع من الاشتقاق " مما ابتدعاء أبو الفتح". فإنّ مفهوم كلام ابن جنّيّ أنّّه

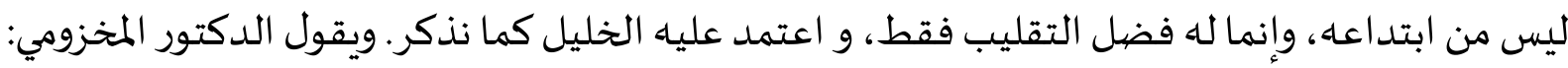

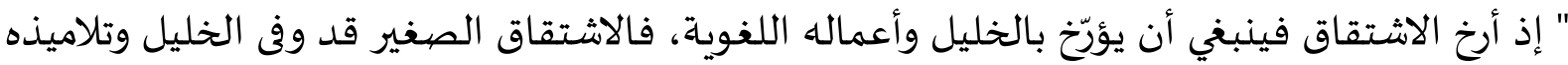

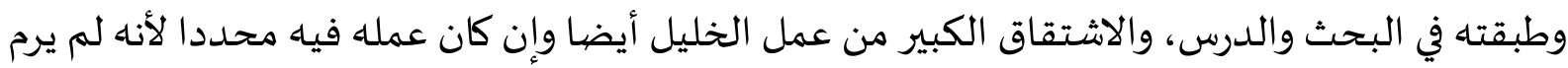

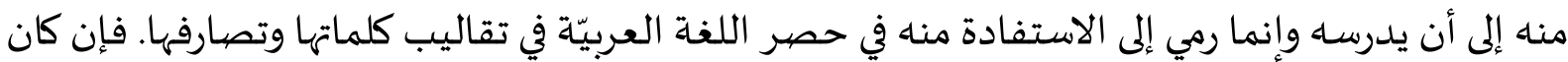

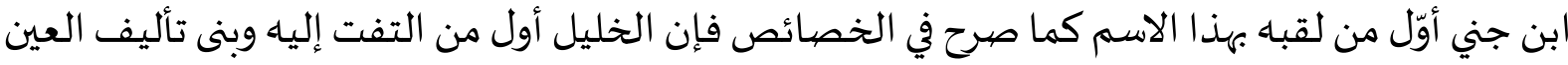

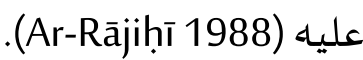

وكذلك ظهرت في القرن الرابع دراسة جديدة للاشتقاق اللغوي، وبقيت عصرا طويلا، وكان أستاذ

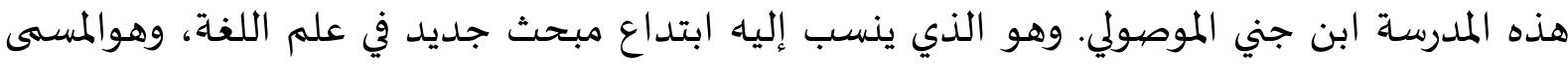

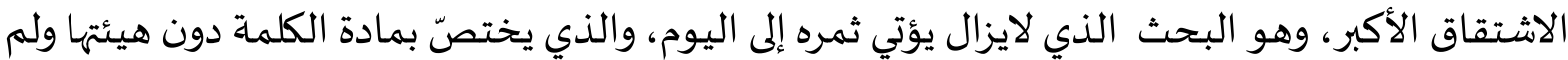

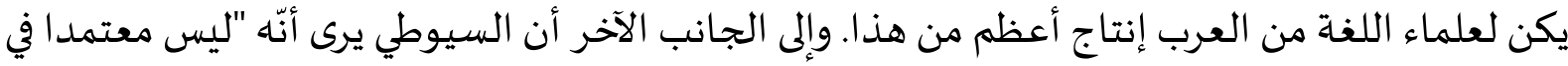

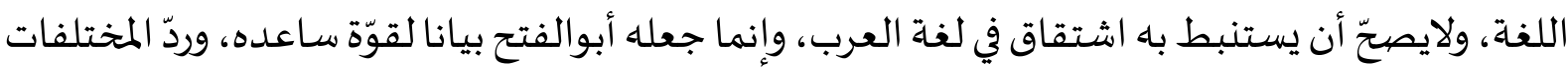
إلى قدر مشترك. ويبدو أنّ الحق في جانب السيوطي لأنّ محاولة الوصول إلى قدر مشترك من المعاني بين

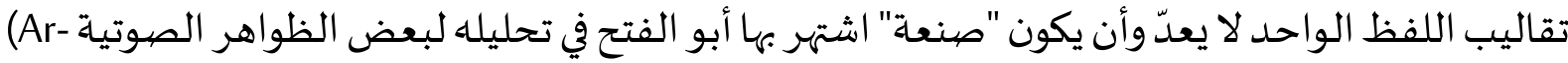

.Rājiḥ̂i 1988)

يوجد وجه الشبه و الخلاف بين آراء ابن جني و السيوطي في النواحي التالية: 
نعتمد من التعريف الذي اطلقه ابن جني أن الاشتقاق الصغير هو أخذ كلمة من كلمة أخرى بتحويل في الصيغة بشرط اجتماعهما في الأصيول والاحرف والمعنى. وعلى سبيل المثال من مادة ( ش ر ح ) وما يتفرّع عنها من شرح ، يشرح ، شرحا ، راشح ، مشروح. أو بعبارة أخرى أن السيوطي يتفق بأراء ابن جني في

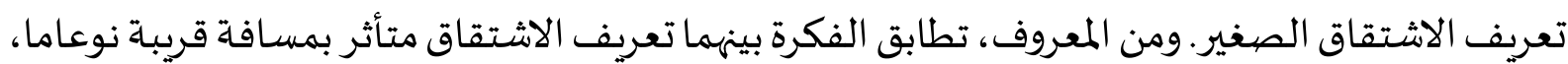
Page | 42 يعني بين القرن الرابع والقرن التاسع. و نرى من التعريف السابق الذي اطلقه ابن جني عن الاشتقاق يشبه بإميل ، أن الاشتقاق الأخذ في الكلام وفي الخصهومة يمينا و شمالا مع ترك القصديد . وأمّا في الاصطيلاح ،

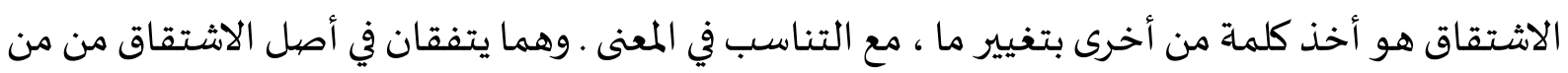
الجواهروالأصهوات المسموعات.

هناك تقسيم الاشتقاق عند ابن جني :() الاشتقاق الصغير r) الاشتقاق الكبير. ولكن اختلف

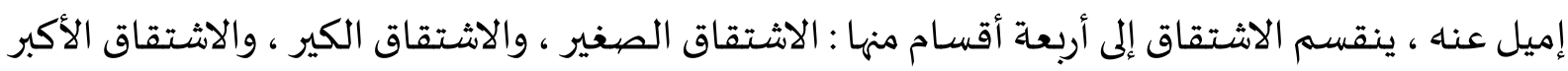

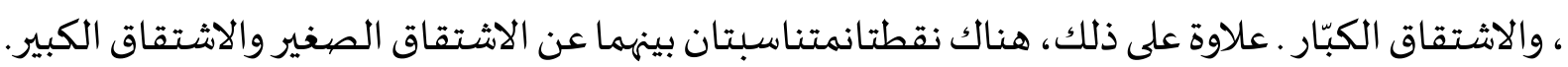
وبالعكس هناك نقطتا الإختلافبينهما، هما في مسألة الاشتقاق الأكبر أو الإبدال و الاشتقاق الكبّار أو النحت.

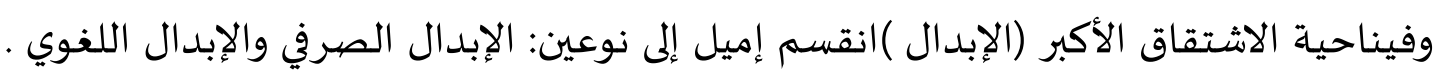
الإبدال الصرفي هو أن تقيّم مكان حروف معيّنة ، حروفا أخرى بغية تيسير اللفظ و تسهيله ، نحو : صام -

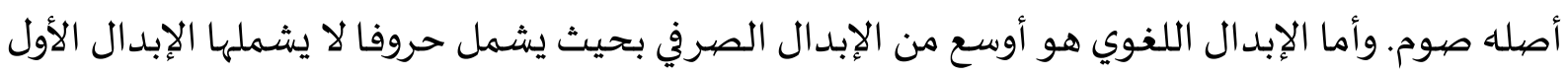

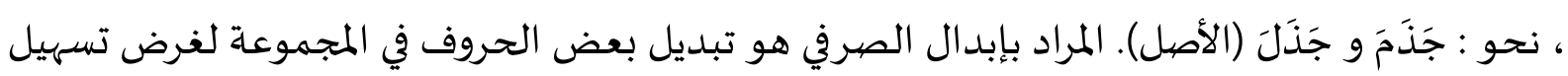
اللفظ ، مثال من لفظ صام - أصله صوم ، أبدل الحرف (واو) في لفظ "صوم " بحرف ( الف) لأجل تيسير في النطق . وأما الإبدال اللغوي هو تبديل بعض الحروف بشرط متقاربة المخرج في المجموعاة لغرض تنوّع اللفظ ، مثال من لفظ جذم - أصله جذل ، أبدل الحرف (ميم) في لفظ "جذم " بحرف ( لام) لأجل تنوّع في اللفظ ـ وقد اعترض إميل أن الإبدال اللغوي مكتوب في معظم كتب اللغة العربية والنحات و ان يكون ظاهرة

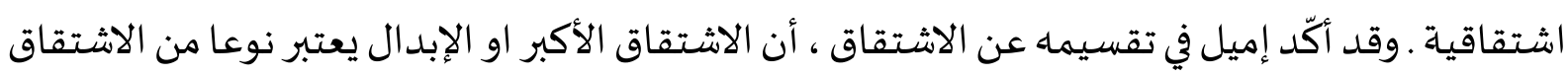
. وقال إميل نقلا من فؤاد ترزي (Ya'qūb 1982) أن الإبدال يتنافى وطبيعة الاشتقاق ، وحجّتّاء: أن الاشتقاق في أسـاسـاه لا يهدف إلى الترادف ولا يؤول إليه . أن ابن جني ، الذي وسَّع مفهوم الاشتقاق إلى حد أدخل فيه القلب اللغوي ، لهم يعتبر الإبدال

$$
\text { ضربا مناه. }
$$

والمراد بتلك الحجة اعلا ها ، ابن جني ينكر القول بأن الإبدال ليس نوعا من الاشتقاق لأنه ظاهرة صوتية فحسب و يحتوي على تقليب بعض الحروف ببعض الآخر. ونتلخّص من البيان السابق ، بأن إميل لا

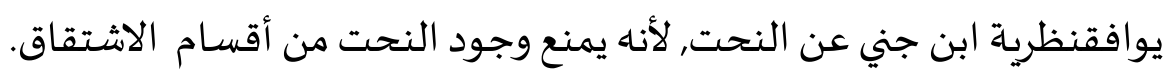

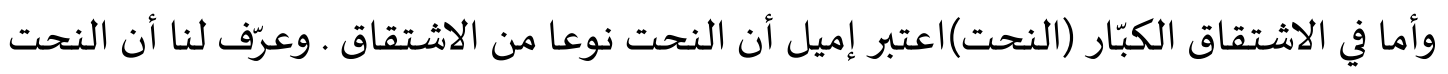

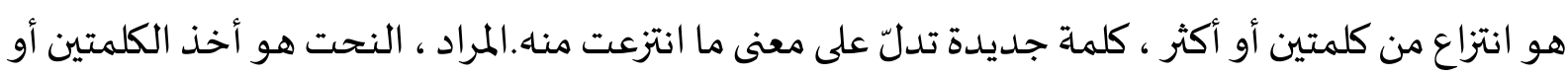
الأكثر الذي تؤدّي إلى كلمة جديدة تشير إلى معنى ما انتزعت منده ، أو في اللغة الإندونيسية تسمى بـ akronim 
. على سبيل المثال : حوقل - أي لاحول ولاقوّة إلّا بالله العليّ العظيم ، بسمل - أي بسم الله الرحمن الرحيم ، وماإلى ذلك . ومن هذا جعل النحت توليد كلمة جديدة عن طريق اختصار الكلمة او الجملة العربية . واختلف موقف اللغويين عن النحت يعتبر نوعا من الاشتقاق أم لا ـ وصرّح إميل في كتابه أن ابن جني أهمل عن بحوث عن النحت ، هذا القول بناء على بيانه (Ya'qūb 1982)النحت غريب عن نظام اللغة العربية Page | $43 \quad$ الاشتقاقي ، لذلك لا يصح أن يعدّ قسما من الاشتقاق فيها. وحجّتـا أن لغويتنا المتقدّمين لم يعتبروه من ضروب الاشتقاق . ونستطيع أن نستنبط أن إميل لا يتّفق بأفكار ابن جني عن النحت ـ لأن اعتبر ابن جني النحت شيئ غريب في اللغة العربية وليس نظامها ـ لذلك منع إبن جني اعتبار النحت نوعا من الاشتقاق . وبعبارة أخربيخالف إميل بآراء ابن جني عن النحت, لأنه منع وجود النحت قسما من الاشتقاق. و نظرا لمسافة

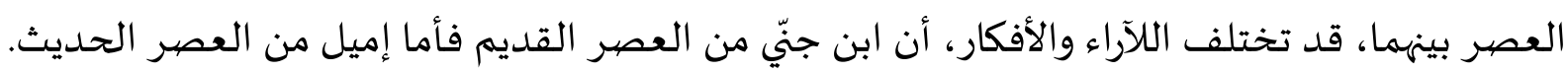
ولكنّ يعطي إميل مساهمة في البحوث الكثيرة التي ظهرت في كلامها في كتاب "فقه اللغة العربيّة وخصائصها" عن الاشتقاق. ففي كتابه نقل كثيرا من أفكار ابن جني والسيوطي والعلماء اللغويين الأخرى.

الخلاصة

قسّم السيوطي الاشتقاق إلى قسمين: الاشتقاق الصغير والاشتقاق الكبير. ويرى أن أصل الاشتقاق من المصدر..والأصل الثاني من الاشتقاق هو الأسماء الجواهر أو الاسماء الأعيان، ولكنّ قليلاجدّا.

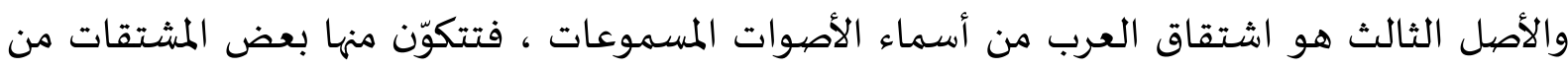

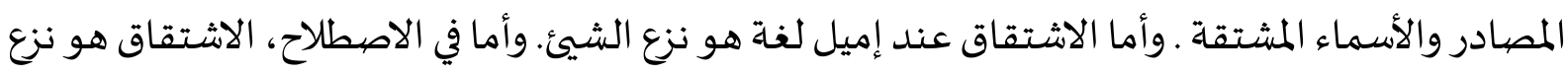

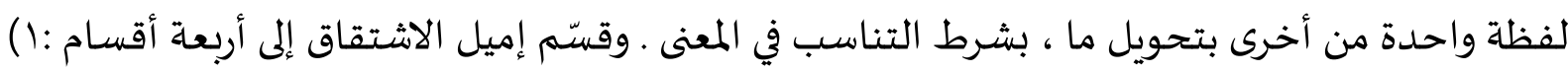

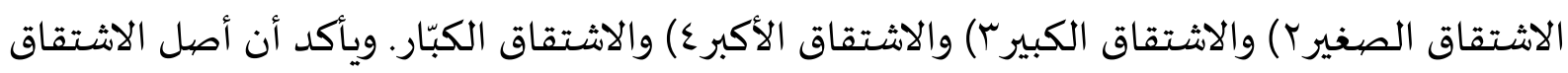

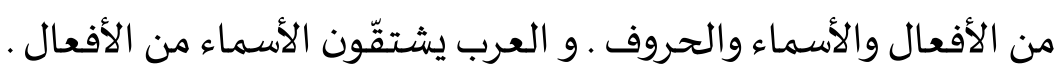
وجدنا نقاط وجاه الشباء بين آراء ابن جني و السيوطي في الأمور الخمسة التالية، فهي:أ) تعريف

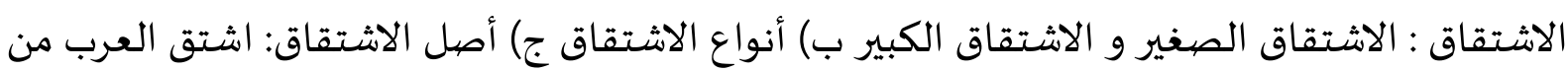
الأسماء الجواهر والأسماء المسموعات. د) الاشتقاق الأكبر (الإبدال). هـ) الاشتقاق الكبّار (النحت). و أما

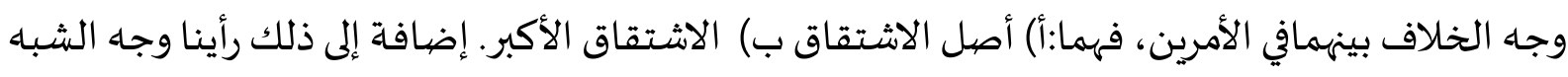
بين آراء ابن جني و إميل في الأمرين، فهما:أ) تعريف الاشتقاق ب) أصل الاشتقاق. وأما وجاه الخلاف بينهمافي الأمور الثلاثة التالية، فهي:أ) أنواع الاشتقاق ب) الاشتقاق الأكبر (الإبدال )ج) الاشتقاق الكبّار (النحت).

\section{اللاستفادة}

ويستند على الخلاصة المذكورة، أخذت الباحثة بعض الاستفادة. الأولى، لمتعلمي اللغة العربية و

دارسي علوم الدين أن يتعمقوا في دراسـة علم الإشتقاق و لا يقتصر على النحو و الصرف. لأن علم الإشتقاق جزء عن علم الصرف ، وميدان دراستاه أعم من علم الصرف. و الكفاءة في علم الإشتقاق سيدعم بشكل مباشر مهارة الطلاب في اللغة العربياةنطقا و كتابة. ومع ذلك سيساعد دارسي علوم الدين لفهم القرآن 
والحديث و الكتب العربية. الثانية، وعلى مسؤولي كلية اللغة العربية ان يضع مادة مخصصية في دراسة الإشتقاق لطلابهم و لو حصية واحدة. لأن علم الإشتقاق من الفن الذي تتميز بـ اللغة العربية عن سائر اللغات. إضـافة إلى ذلك علم الإشتقاق لله علاقة مباشرة بعلم الصرف و الحضيارة و جزء من تاريخ اللغة و

$$
\text { الشعر العربي الذي لا ينفصل من علم القوافي. }
$$

Page $\mid 44$

Al-Khūli, Muhammad 'Ali. 1998. Dirāsat Al-Lughawiyah. Place of publication not identified: Dar al-Falāh For Publish.

Al-Suyūțī, Jalāluddīn. 2014. Al-Muzhir Fì 'Ulūm Al-Lughah Wa Anwā'uhā.

Amīn, 'Abdu Allāh. 1956. Al-Ishtiqāq. al-Haiah al-Mishriyah al-'Ammah. https://books.google.co.id/books?id=f174QwAACAAJ.

Ar-Rājiḥī, Sharifuddin 'Alī. 1988. Shibhu Al-Jumlah Fì an-Nahwi Al-'Arabī Wa Al-Qur'ān AlKarīm. Maktabat 'Ālim al-Fikr wa al-Qanūn. https://books.google.co.id/books?id=SLeCQgAACAAJ.

Fauzia, Eva Lathifah. 2019. "Ikhtilāfāt Dirāsat Ilm Așwāt Bayna Al-'Arabiyah Wa Al-Lisāniyah AlHadīthah." ALSUNA: JOURNAL OF ARABIC AND ENGLISH LANGUAGE. https://doi.org/10.31538/alsuna.v2i1.313.

Jinnī, Ibn. 1952. Al-Khașāiș. Al-\{Kha\} S a i S. Dar al-Hudā. https://books.google.co.id/books?id=OcZiAAAAMAAJ.

Jurjī, Zaidān. 1990. Al-Falsafah Al-Lughawiyah Wa Al-Alfāẓ Al-'Arabiyah. Dar al-Hilāl. https://books.google.co.id/books?id=h7wZAQAAIAAJ.

Maknunah, Lu'luil. 2008. “Al-'Alāqah Bayna Al-Ma'ānī Wa Ahrufihā Li Al-Ishtiqāq Al-Akbar Aw Al-Qalb Al-Lughawī." UIN Malang.

Qadūr, Aḥmad Muhammad. 1993. Madkhal Ilá Fiqh Al-Lughah Al-'Arabiyah. Dar al-Fikr alMu'așir. https://books.google.co.id/books?id=yP50QgAACAAJ.

Rosyidah, Inayatur. 2009. "Dirāsat Al-Muqāranah 'an Al-Ishtiqāq 'Inda Ibn Jinnī Wa Al-Suyuțī Fī Al-Muzhir." UIN Malang.

Ya'qūb, Emīl Badī'. 1982. Fiqh Al-Lughah Al-'Arabiyah Wa Khașāișuhā. Dar al-Ilm Li al-Malayīn. https://books.google.co.id/books?id=b-QrAAAAMAAJ.

Zainuddin, Ammar, and Hasyim Asy'ari. 2019. "Bunyat Al-l'jāz Fī Al-Qur'ān Al-Karīm: Dirāsah Lughawiyah 'Inda Abdul Qāhir Al-Jurjānī." ALSUNA: JOURNAL OF ARABIC AND ENGLISH LANGUAGE. https://doi.org/10.31538/alsuna.v2i1.312. 